\title{
The Horizontal Mechanism Initiative in the WTO: The Proceduralist Turn and Its Discontents
}

\author{
A kbar Rasulov*
}

$\underline{\text { Introduction }}$

It has long been the received wisdom among international lawyers that the natural course of historical progression for the international legal system entails a process of steady but everdeepening judicialization of international dispute settlement (IDS). The more developed and more sophisticated the international legal system became, the more ubiquitous would become the use of international judicial mechanisms, the more decisively the centre of gravity in IDS would move away from what in other legal systems would be considered alternative dispute resolution structures tow ards some form of litigative or quasi-litigative procedure.

Whether this theory was ever justified as a matter of factual historical record, remains, of course, in considerable doubt. Latterly, however, it seems, in addition to everything else, it has come on hard times also as a matter of international policy vision - nowhere more so vividly, perhaps, than in the field of international economic law. The remarkable decision by the German government in M arch 2014 to push for the exclusion of any form of investorstate IDS mechanism from the Transatlantic Trade and Investment Partnership agreement provides only the most recent illustration of what seems to be a gradually spreading trend. ${ }^{1}$

This emergent pattern of deep-seated ambivalence concerning the use of judicial IDS mechanisms has not, of course, remained the sole provenance of international investment law policymakers. Over the last few years, indeed, it seems to have become a rather familiar theme in various international trade law (ITL) circles as well. The ongoing attempt since the middle of the last decade to reform the standard procedures for the 'facilitation of solutions to non-tariff barriers' in the context of the World Trade Organization (WTO) - the so-called Horizontal M echanism (HM) initiative - offers a brilliant case in point.

In this essay I propose to address some of the issues raised by the emergence of the HM initiative and the respective transformations in the ITL consciousness which it seems to reflect. M ore specifically, I am going to describe a number of fundamental challenges which the rise of the HM initiative seems to have uncovered within the broader structure of the ITL project, challenges that I am going to argue are not, in fact, at all exclusive to the ITL field as such but are, indeed, characteristic of the entire enterprise of contemporary international law as a whole. ${ }^{2}$

\footnotetext{
${ }^{*}$ School of Law, University of Glasgow.

${ }^{1}$ For background, see Shawn Donnan and Stefan Wagstyl, 'Transatlantic Trade Talks Hit German Snag', F inancial Times, $14 \mathrm{M}$ arch 2014; electronic copy available at $h \mathrm{ttp}: / / \mathrm{www}$.ft.com/cms/s/0/cc5c4860-ab9d-11e390af-00144feab7de.html \#axzz32r6s6a8t.

${ }^{2}$ On the concept of international law as a 'project' or 'enterprise', see further M artti Koskenniemi, The F ate of Public International Law: Between Technique and Politics, 70 M od. L. Rev. 1 (2007); David Kennedy, A New World Order: Yesterday, Today, and Tomorrow, 4 Transn'I L \& Contemp. Probs. 329 (1994).
} 
A large part of the argument I am going to sketch out in these pages is fairly unoriginal. What it lacks in terms of originality, however, it tries to make up for in terms of its theoretical urgency. It seems to me truly extraordinary how little attention has been paid in the broader doctrinal and policymaking debates that have sprung around the question of the $\mathrm{HM}$ initiative in recent years - and more generally in contemporary ITL as a whole - to the kind of issues and insights which the sort of analysis outlined here helps identify and articulate. Given how relevant these insights are for other areas of international economic governance too, this pattern of omission seems both baffling and suggestive of a rather worrying trend.

Since the theoretical intervention that I would like to make in this essay is not intended to double as a literature review, I have refrained from discussing in these pages every single piece of writing that seeks to make a contribution to the HM 'debate'. For the purposes of the argument that I wanted to make here, it was sufficient to focus only on the most characteristic representative of the genre. ${ }^{3}$ This I found in a recent article written by Veronique Fraser. ${ }^{4}$ This choice, inevitably, is not immune to challenges. But then neither is any other interpretative decision, and this one at least has the merit of being transparent. ${ }^{5}$

\section{A B rief Genealogy of the HM Initiative}

The basic timeline behind the HM initiative looks as follows.

Building on the various successes of the previous decades, in 2001, WTO members embarked on a new round of multilateral trade negotiation (the so-called Doha Round). One of the central concerns placed on the negotiators' agenda was the spread of the so-called non-tariff barriers (NTBs) in international trade. Though a clearly defined substantive conception of NTBs had proved traditionally impossible to work out - even today the standard definition vacillates between the decidedly elastic 'any policy measures other than tariffs that can impact trade flows' ${ }^{6}$ and a somewhat more functional but still very broad 'all non-tax measures imposed by governments to favour domestic over foreign suppliers' ${ }^{7}$ - the commitment to address the mischief caused by these trade-restrictive mechanisms remained firm.

The common assumption established at the time held that for decades NTBs had not played a significant role in international trade. The reason this stopped being the case was the continuing success of the GATT/WTO enterprise. The progressive development of the GATT disciplines relating to tariffs over the previous decades had steadily increased the relative attractiveness of other instruments of protectionism. Because, unlike tariffs, NTBS

\footnotetext{
${ }^{3}$ In making this choice I was influenced by the methodological discussion in CARLO GINZBURG, THREADS AND TRACES 213-3 (2012).

${ }^{4}$ Veronique Fraser, Horizontal Mechanism Proposal for the Resolution of Non-Tariff-Barrier Disputes at the WTO: An Analysis, 15 JIEL 1033 (2012).

${ }^{5}$ Further on the subject of interpretation being a fundamentally decisionistic process, see, e.g., UMBERTO ECO, THE ROLE OF THE REAdER: EXPLORATIONS IN THE SEM IOTICS OF TEXTS (1979).

${ }^{6}$ Robert Staiger, 'Non-Tariff Measures and the WTO', WTO Economic Research and Statistics Division, W orking paper ERSD-2012-01 (2012) at 2.

7 See Jörg Philipp Terhechte, 'Non-Tariff Barriers to Trade', in MAX PLANCK EncyCLOPEDIA OF INTERNATIONAL LAW (2013), at para. 1.
} 
historically have tended to be fundamentally non-transparent in their purpose and effects, and because in many cases their application could be easily justified on grounds that formally had nothing to do with trade, their trade-distortive potential was quickly realised both by governments and the various special interests clamouring trade protection. ${ }^{8}$ The use of NTBs increased. What is more, it also became progressively more sophisticated: if prior to the U ruguay Round NTBs most commonly took the form of import quotas, voluntary export restraint agreements, and non-automatic import licenses, the post-U ruguay trend has seen the use of these trade control devices significantly diminished in favour of other, less easily quantifiable and analysable mechanisms. ${ }^{9}$

Even though the empirical evidence in its support was not unequivocal, the common impression by the start of the new century thus became that the centre of gravity in NTB practices had increasingly shifted away from the relatively easy to trace measures, such as quotas and non-automatic licenses - what one might call old-style NTBs - towards the fundamentally more difficult to 'expose' instruments, such as technical standards, customs procedures, and SPS measures ${ }^{10}$ - the new-style NTBS - devices which, because of their mixed legitimation dynamics, were, furthermore, even more difficult to measure for their trade-distortive effects in practice. ${ }^{11}$

In response to such developments, an entirely new policy initiative framework, it was decided, had to be put in place. As part of this framework and in furtherance of the Doha Round's more comprehensive vision for trade liberalisation a special Negotiating Group on Market Access for Non-agricultural Products (NAMA) was established in early 2002. Designed to serve, among other things, as the WTO's primary institutional locus for all work aimed at the reduction or elimination of NTBs in the WTO context, NAMA's efforts in the area to date have proceeded along two main avenues: the identification, categorization, and examination of the different types of NTBs used in current global practice and the development of corresponding solutions and approaches to NTB negotiations. ${ }^{12}$

In the course of its work the group has prepared a number of comprehensive negotiations proposals - the so-called NAMA modalities - the most recent of which was issued on 6 December 2008. The aim of such proposals is to set out a draft roadmap for the subsequent negotiations on market access that would be followed by the WTO members. A n important source of inspiration in determining the content of these draft roadmaps have been the individual proposals and initiatives submitted by various participating member states or groups of member states.

The HM initiative, originally proposed by the so-called NAMA-11 group and the European Communities, was first entered into this process of policy collation in $M$ ay $2006 .{ }^{13} \mathrm{~A}$ fter

\footnotetext{
${ }^{8} \mathrm{~F}$ or a standard rehearsal of this argument, see Edward J ohn Ray, Changing Patterns of Protectionism: The $F$ all in Tariffs and the Rise in Non-Tariff Barriers, 8 N w. J. Int'I L. \& Bus. 285, 302-8 (1987).

${ }^{9}$ See OECD, Looking Beyond Tariffs: The Role of Non-Tariff Barriers in World Trade (2005), at 12.

${ }^{10}$ Thus, the authors of a 2005 OECD study on the subject observe: 'Today, exporters around the world are preoccupied less by traditional border measures, such as import or export licensing, quotas and prohibitions than by difficulties arising from product standards, conformity assessments and other behind-the-border policies in importing countries.' (Ibid.)

${ }^{11}$ Ibid., 13.

${ }^{12}$ Terhechte, supra n.7, para. 19.

${ }^{13}$ See WTO, N egotiating Group on M arket Access, 'M arket A ccess for N on-A gricultural Products: Resolution of NTBs through a Facilitative Mechanism', TN/MA/W/68/Add.1 (5 May 2006). See also European
} 
undergoing a series of variously significant amendments, it found its most commonly recognisable shape in a reformulated proposal sponsored by some 88 WTO member states that was tabled on 3 February $2010 .{ }^{14}$ It is this version of the HM 'vision' that remains today at the focus of the respective doctrinal debates.

\section{The Internal Structure of the HM Discourse}

Most discussions of the HM initiative follow the same script: they adopt a conspicuously technocratic tone, they present arguments light on history and hard data, and they build their narrative structures around three principal themes.

The first theme addresses the question of the overall purpose behind the HM initiative. According to the standard account, the principal objective of introducing the new mechanism is to 'assist in the resolution of NTB disputes', and the general presumption behind this is that this aim can be best attained by inserting the new IDS mechanism within the al ready existing procedural setup, rather than by establishing some new procedural channel. ${ }^{15}$ The basic conception thus outlined projects an impression of a policy programme geared towards evolution, organic growth, and modest piecemeal reform, but never radical reconstruction: '[t]he topic seems to be too complex for a "big solution"', runs the common refrain. ${ }^{16}$ The spirit of radicalism and sweeping utopian visions has no place in the NTB landscape. A pragmatic approach grounded in a realistic set of ambitions is the order of the day.

The second theme concerns the question of what sort of immediate institutional arrangements would best serve to realise this conception in practice. Two main points are commonly stressed in these discussions: (i) the new mechanism should work exclusively on the basis of the principle of consent, and the search for mutually acceptable solutions should remain the key priority at all stages; and (ii) to assist the parties in developing such solutions, it would be a good idea, after an initial stage of bilateral consultations, to introduce into the picture some kind of independent facilitator.

The basic setup that is reflected in the 2010 version of the $\mathrm{HM}$ proposal ${ }^{17}$ reflects this vision as follows: at the first stage of the proceedings, the parties would be given the chance to resolve the matter between themselves bilaterally. The requesting member would have to submit in writing a request for information concerning a specific NTB to the responding member: the request should detail the immediate measure in question but also explain the grounds for the requesting member's concerns (\$6). The responding member would then have up to twenty days to prove a written response (\$7), a copy of which together with the copy of the request would be passed on to the respective WTO Committee to be circulated to the WTO membership (\$8). If at that point, the requesting state's concerns still remain

Communities, 'N egotiating Proposal on WTO M eans to Reduce the Risk of Future NTBs and to Facilitate Their Resolution', TN/M A/W/11/A dd.8 (1 M ay 2006).

${ }^{14}$ See WTO, N egotiating Group on M arket Access, ' $M$ inisterial Decision on Procedures for the Facilitation of Solutions to N on-T ariff Barriers', TN/M A/W/106/Rev.1 (3 February 2010).

${ }^{15}$ Fraser, supra n.4, 1040.

${ }^{16}$ Terhechte, supra n.7, para. 18.

${ }^{17}$ See supra n.14. 
unresolved, and if both the requesting state and the responding state so agree, the proceedings would progress to the second stage $(\S 9)$ and an independent facilitator would be appointed $(\S 12)$. The parties can request the chairperson of the relevant Committee or one of the vicechairpersons to serve as the facilitator, or agree on an entirely external candidature who would serve in the capacity of 'a friend of the chair' (§12). If the parties cannot agree on who should serve as the facilitator, the chairperson of the relevant Committee may, upon request by one of the parties, appoint the facilitator him or herself $(\S 12)$. Obviously, if the other party would not be content with the choice, it could always request that the proceedings be terminated altogether (\$11bis). The facilitator's principal functions would include organizing the meetings between the parties, consulting on their behalf with the relevant WTO structures, offering advice, and proposing possible solutions (§15). In fulfilling these functions, the facilitator would be entitled to receive any information from either of the parties as well as from the relevant WTO structures, experts and stakeholders whom he or she would be entitled to consult, subject to the parties' agreement (§15). All meetings and information acquired in this process would be treated as confidential and would not be subject to prejudicial use in any future WTO judicial proceedings (§17). All in all, the second stage would last up to sixty days from the date of the appointment of the facilitator $(\S 16)$. Whether or not in the end a satisfactory resolution would be achieved, the facilitator would prepare an independent factual report, outlining the issues raised during the discussions and the solutions proposed thereto. The report, with the accompanying comments from the parties, would then be passed on to the relevant WTO Committee and added to the record (§18). A t no point would this report be treated as providing a commentary on the parties' legal position or an interpretation of the WTO A greement (§18).

It is unclear to what extent the authors of the 2010 proposal consciously took into account what one might call the traditional dogmas of IDS theory. However, it seems quite remarkable how closely the proposed setup reflects the conventional accounts of mediation and conciliation adopted in the classical IDS doctrine. Consider, for instance, what the latter typically has to say on the subject of mediation:

By accepting mediation, a government acknowledges that its dispute is a legitimate matter of international concern. If, therefore, a question of international accountability lies at the heart of the controversy, ... mediation will be out of the question. M oreover, a mediated settlement is al ways likely to be a compromise of some kind. [Thus, m]ediation is likely to be particularly relevant when a dispute has progressed to a stage which compels the parties to rethink their policies. A stalemate is clearly one such situation; another is when the parties come to recognise that the risks of continuing a dispute outweigh the costs of trying to end it. ... The value of mediation as a source of information should not be overstated. ... There is ... no guarantee that the information brought by a mediator [, e.g., in the form of a final report] will always be believed; nevertheless, its presence will certainly tend to discourage wishful thinking, while sometimes providing critics of official policy (whose pressures may be important in encouraging a settlement) with a source of valuable intelligence. ${ }^{18}$

The parallels with the 2010 proposal are numerous and very easy to spot. The consistent foregrounding of compromise; resistance towards any prospects of allowing the question of

${ }^{18} \mathrm{~J}$. G. MerRills, International Dispute Settlement $29-34$ ( $5^{\text {th }}$ edn.; 2011). 
accountability and thus of legal status to be raised at any point during the proceedings; ${ }^{19}$ the introduction of a two-stage process to prepare the ground for the 'rethinking of the policies'; the insistence on the publication of the mediator's report and the treatment of (partial) transparency as a good in itself - one almost gets the sense that the authors of the 2010 proposal made a conscious effort to make it look like it had been 'written by the book'.

Nor is that all. Consider now how the IDS doctrine typically conceptualises conciliation:

One view is that it is to be regarded as a kind of institutionalised negotiation. The task of the [conciliator] is to encourage and structure the parties' dialogue, while providing them with whatever assistance may be necessary to bring it to a successful conclusion. This approach, which proceeds from the premise that the resolution of disputes depends on securing the parties' agreement, finds an affinity between conciliation and mediation ... A [conciliator] has a duty to examine the nature and background of a dispute and so is usually equipped with wide powers of investigation. Unlike an inquiry, however, whose whole raison d'être is to illuminate the dispute, a [conciliator] has as [his] objective the parties' conciliation. [His] investigative powers are thus simply a means to an end. As a result, if it becomes apparent that the exposure of some matter might make conciliation more difficult, that line of investigation is unlikely to be pursued. ... [0]ne of the distinctive features of conciliation is that [the final] report takes the form of a set of proposals, not a decision. Thus, even in cases where law has been a major consideration, the report is quite different from an arbitral award and not binding on the parties. This feature of conciliations [presents] something of a dilemma. On the one hand, [the conciliators] wish to make their proposals as persuasive as possible by supporting them with reasons; on the other hand, they are unwilling to provide the parties with legal arguments or findings of facts that may be cited in subsequent litigation. [N evertheless, it has to be noted that, as a mechanism of IDS, c] onciliation has so far proved most useful for disputes where the main issues are legal, but the parties desire an equitable compromise. [B]ecause of the way conciliation is conducted - through a dialogue with and between the parties - there is no danger of it producing a result that takes the parties completely by surprise, as sometimes happens in legal proceedings. Secondly a [conciliator's] proposals ... are not binding and, if unacceptable, can be rejected. ${ }^{20}$

The parallels, once more, are rather difficult to overlook: an equitable resolution for issues that are legal in character; a final report that is all about outlining proposals and not preparing the ground for subsequent litigation; proposals that are all about persuasion but are not binding; considerable independent investigative powers subject to the understanding that if the parties are not happy about a certain line of investigation (e.g. the use of a certain group of independent experts), it should be immediately abandoned.

Now, this is not at all a certain fact - and it most definitely is not the only thing that is probably happening beneath the surface of the HM initiative - but it seems to me that one very possible scenario that needs to be considered at this point, in trying to explain this turn to 'writing by the book', is that the more successfully the authors of the 2010 proposal have managed to express the idea that the HM proposal they were sponsoring had been modelled on the traditional concepts of mediation and conciliation, the more successfully they would

\footnotetext{
${ }^{19}$ Fraser even goes so far as to propose an additional provision to the HM procedure enjoining the facilitator from using any kind of writing style that may be interpreted as 'presenting a legal evaluation of the parties' case'. (Fraser, supra n.4, 1051.)

${ }^{20}$ M ERRILLS, supra n.18, 65-81.
} 
thereby have also conveyed the message that it was not at the same time intended to be considered under the rubric of the judicial IDS.

In a sense, this is basic Saussurean semiotics in action: since all meaning is relational, i.e. derived from the logic of differences and oppositions (' $A$ ' is that which is both not ' $A$ ' and not 'non $\left.A^{\prime}\right),{ }^{21}$ the easiest way to ensure that one' $s$ audience does not get the impression that one is talking of a certain phenomenon would be to use persistently those vocabularies which in the mind of this audience are associated with the exactly opposite phenomena.

In the internal conceptual taxonomy adopted by the traditional IDS theory, both mediation and conciliation operate as categories whose basic identity is defined to a very large extent through their distance from, and dissimilarity to, arbitration and judicial settlement, i.e. the judicial IDS mechanisms. Looking at the standard patterns of the HM discourse from this angle, the consistent deployment of the classical tropes of mediation-ism and conciliation-ism suddenly seems not at all unrelated to the regular invocation in the same context of the idea that 'whatever the outcome, the HM procedure will neither address nor alter the legal positions of the parties'. For, indeed, even the briefest scrutiny of the broader HM discourse suggests that this motif is not of episodic importance.

$$
* * * *
$$

The third theme around which most of the discussions in the contemporary HM debate revolve has for its focus the question of the general strategy of institution-building, that is to say, the overall plan on the basis of which all those practical details outlined above have been developed.

This plan, in a nutshell, seems to consist of two chief elements, each of which is defined in terms of a fundamental end-goal to be achieve through the institution of the new mechanism.

The first goal is the improvement of the existing institutional potential of the respective WTO Committees. The strategic plan envisages that the new procedures would be carried out strictly within the limits of the established WTO Committee framework and would apply 'to any non-tariff measure that is within the remit of a covered WTO Committee', which is defined as the Committee charged with 'overseeing the operation of the WTO agreement

\footnotetext{
${ }^{21}$ For a quick introduction to Saussurean semiotics, see DANIEL CHANDLER, SEMIOTICS: THE BASICS (2 ${ }^{\text {nd }}$ edn.; 2007). In a nutshell, Saussurean semiotics (there exist al so other varieties) is distinguished by its presumption that the production of meaning cannot be understood in terms of some essential or intrinsic facts (content) which the words (signs) we use to describe these facts (content) are meant to represent. The reason for this is that 'signs refer primarily to each other': 'no sign makes sense on its own, but only in relation to other signs'. 'This notion can be hard to understand since we may feel than an individual word such as "tree" does have some meaning for us, but Saussure's argument is that its meaning depends on its relation to other words within the system (such as 'bush').' (ibid., 19) 'Saussure's relational conception of meaning was specifically differential: he emphasized the differences between signs. Language for him was a system of functional differences and oppositions. ... Saussure emphasized in particular negative, oppositional differences between signs. He argued that "concepts ... are defined not positively, in terms of their content, but negatively by contrast with other items in the same system. What characterizes each most exactly is being whatever the others are not." This notion may initially seem mystifying if not perverse, but the concept of negative differentiation becomes clearer if we consider how we might teach someone who did not share our language what we mean by the term "red". We would be unlikely to make our point by simply showing that person a range of different objects which all happened to be red - we would probably do better to single out a red object from a set of objects which were identical in all respects except colour.' (Ibid., 21.)
} 
most closely related to the measure at issue'; if no such Committee exists for the particular class of measures, the coordinating structure will be the Council for Trade Goods. ${ }^{22}$

The second goal set out in the strategic plan is the facilitation of the emergence of a more efficient multilateral process of information gathering, discussion, and negotiations that will not lead to any kind of 'legalistic evaluation' of the member states' rights and obligations under the respective parts of the W TO agreement.

Note the double emphasis: the 2009 briefing paper ${ }^{23}$ prepared on behalf of the then coalition of sponsors (its composition has since changed) puts a very clear premium on the idea that the resolution of any given NTB dispute is not, ultimately, an issue in which only the two immediately involved states alone have a valid stake. To resolve the problem of NTBS effectively, requires the achievement of the 'highest possible transparency of procedure' and the balancing of 'the interests of the [immediate] parties to come to a mutually agreed solution' with the legitimate 'interests of other WTO members' ${ }^{24}$ Although the drafters of the paper do not immediately clarify what those legitimate interests might include, from the overall context of the discussion it seems clear that the main concern here is to enable the creation of an effective regime for the accumulation of information that could be used in the future by any member state or the interested WTO structure. ${ }^{25}$ (Note again the continuous pre-occupation with the concept of information gathering; I will return to this point shortly.)

The language of 'legalistic evaluation' comes from the same briefing paper. The wording may seem a little unusual - the term 'legalistic' clearly has pejorative connotations and would normally be associated with the writings of Hans M orgenthau, not WTO policy discourse but it is certainly not without wider significance. A close reading of the accompanying discussions suggests that the invocation of this phrase is designed to perform two slightly different functions in the present context: in the first place, it fixes what seems to be the most important element in an otherwise fundamentally vague explanation (see the point about semiotics above: the best way to explain what something is to indicate what it is not); in the second place, it very efficiently conveys the HM sponsors' general theory about NTB disputes.

What are the main defining elements of this theory? The answer can be gleaned in part from an earlier passage in Fraser's essay:

NTBs are trade barriers that have the effect of restricting imports [but] NTBs can [also] serve legitimate objectives and important purposes pursued by $\mathrm{M}$ ember States. They are expressly permitted under the WTO agreements when they are deemed to protect human, animal or plant life or health, or the environment. ... Due to their antagonistic nature, which on one hand serves legitimate purposes of governments, and on the other hand, restricts trade, NTBs can be the object of many disputes between M ember States. ${ }^{26}$

\footnotetext{
${ }^{22}$ Fraser, supra n.4, 1042.

${ }^{23}$ See WTO N egotiating Group on M arket Access, ' $M$ arket A ccess for N on-A gricultural Products: A nswers by the co-sponsors to Questions raised during Chair's NTB session of 19.03.2009 regarding the proposed "M inisterial Decision on procedures for the facilitation of solutions to non-tariff barriers"', TN/M A/W/110 (16 A pril 2009).

${ }^{24}$ Ibid., para VII.1.

${ }^{25}$ See, in particular, ibid., paras I.1 and VII.3.

${ }^{26}$ Fraser, supra n.4, 1036.
} 
M ost of these disputes, continues the argument, are unlikely, however, to be brought forward through the standard WTO legal channels - and precisely for the same set of reasons al ready mentioned: many measures which result in the creation of NTBS are adopted for the protection of fundamentally important social values the advancement of which is expressly permitted under the WTO law. Any attempt to challenge their legitimacy, follows the conclusion, is bound to result in such tremendous political acrimony that any potential gains will not be worth the costs. As another commentator puts it, 'in the area of NTBs national interests play [such] a pivotal role [that they] often cause States to refrain from formal disputes. ${ }^{27}$ Lest these latent disputes be allowed to simmer indefinitely, a more informal IDS mechanism has to be provided.

Or, at least, that is the basic understanding which the standard account seeks to promote. Recall the basic sequence implied by Fraser's argument: (i) there seems to be something very distinctive about NTB disputes themselves as a result of which they tend to become extremely resistant to 'legalistic' resolution; (ii) this something can be best explained in terms of the fact that NTB disputes are characterised by a deeper than usual level of complexity in their legitimacy dimension, that is to say, the role of policy considerations in their case seems to be far higher than in the case of most other WTO disputes; (iii) 'legalistic' institutional frameworks are not the best forum for the resolution of policy conflicts; (iv) hence the conclusion that a new, more 'flexible and expeditious procedure[] of a conciliatory and nonadjudicatory nature' is needed. ${ }^{28}$

Now, compare this implied sequence to the actual argument itself. Consider, in particular, the loose combination of two sweeping generalisations and a logical leap that are quietly imported into the argument structure to enable its smooth progression: surely, it would be inaccurate to suggest that all NTB disputes are characterised by the same degree of policy indeterminacy, right? Indeed, Fraser's second comment in the passage quoted above seems to recognise exactly that fact, since she writes 'NTBs can [also] serve legitimate objectives and important purposes'. The choice of the verb is not insignificant: not all measures that can, do. In her first comment, just before that, Fraser states that all NTB measures have the effect of restricting trade. In formal-logical terms, this statement follows the standard formula of a universal proposition: all A are B. W hat Fraser says in her second comment, by contrast, does not have the same intonation: all NTB measures can serve legitimate social purposes, which means that in practice only some of them do and others do not. The logical formula that is deployed here is that of a particular proposition: some $A$ are also $C$. So far, so clear, but notice now how Fraser then goes on to rearrange these two statements at the start of her third comment, just before she explains the reasons for why legalistic IDSs are not going to be a good forum for NTB disputes: because NTB measures serve legitimate objectives and at the same time result in trade restrictions, NTB disputes are likely to give rise to particularly acrimonious disputes. Notice the sudden shift from 'all $A$ are $B$, and some $A$ are also $C^{\prime}$ to 'all $A$ are $B$ and all $A$ are also $C$ '. W hat is going on here?

For starters, it is a basic rule of formal logic that a combination of a universal proposition about NTBs and a particular proposition about NTB s cannot yield a logically valid universal conclusion about NTBs. If Fraser had not rephrased the basic statement at the heart of her second comment when she repeated it at the start of her third comment, she would not have

\footnotetext{
${ }^{27}$ Terhechte, supra n.7, para. 34.

${ }^{28}$ Fraser, supra n.4, 1040.
} 
been able to produce a convincing argument about an irresolvable contradiction whence the suggestion about particularly awful acrimony would arise.

Furthermore, the proposition that some measures which lead to the creation of NTBs may al so, under certain circumstances, be used to protect fundamentally legitimate social values is valid, strictly speaking, only for a very limited class of such measures. Given the established doctrinal consensus, it would be hard to imagine that an old-style NTB, such as an import quota or a voluntary export restraint, could ever be recognised as serving a fundamentally legitimate (from an ITL point of view) social purpose in the normal course of international trade. If there is one thing on which all NTB commentators today seem to agree, it is that from the 'good policy' point of view, outside situations of extreme economic emergency, such devices will have no redeeming features. By the same token, it is equally unclear how one could ever make in the same context a convincing argument that the meaning of 'fundamentally legitimate social values' could be extended in such a way as to cover, for example, a situation where the importing state changes its customs certification procedure from a model that mandates the importer to complete ten separate forms to one that mandates the completion of fourteen forms.

None of this is to suggest, of course, that in its general contours Fraser's proposed explanation and the argument constructed in its support do not work. They most certainly do - and that is precisely the whole point: like so much else about the NTB discourse, they work but only in their general contours, at the most abstract level, that is to say, so long as one does not inspect them very closely, trace their logical formulas too diligently, or ask for too many practical illustrations and specific examples. A $n$ argument that cannot withstand close inspection, an explanation that relies on hidden logical slippages for its ability to hold together, a discourse that operates smoothly only when it deals in abstract generalities - in the critical studies tradition such an arrangement of intellectual conditions is typically taken to be a sign that one is getting dragged into the middle of a heavily ideological exercise - in the most vulgar sense of the word possible.

\section{The External Structure of the HM Discourse}

When it comes to the question of addressing any given set of challenges to the enterprise of trade liberalisation, the contemporary ITL doctrine recognises three main possibilities.

The first possibility involves the delegation of the respective issue to the respective WTO Committees and other similarly placed executive and deliberative structures. This is the rubric under which the HM initiative belongs. The popular view holds that this approach offers the greatest amount of flexibility, but that it works best when the stakes involved are either relatively low (so as not to excite any digging-in of the heels on the part of the involved players) or relatively high (so that diplomacy by definition becomes the only realistic option). When it comes to situations involving stakes of medium-range proportions, the procedure often falters. W ith regard to the NTB problem, for example, the common impression is often that the absence of a stricter operative code in such institutional settings means that 'the discussions over a NTB concern [will typically] occur in an unstructured manner and without 
any timeframe, [which] restrains its potential of being resolved. ${ }^{29}$ The statement may seem observationally correct. And yet it is, in fact, deeply illogical. It is precisely because these settings offer the possibility to the parties concerned to engage in an unstructured discussion without any rigid timeframes that these procedures exist at all. To complain about the fact that they have these characteristics is, effectively, akin to feeling scandalized that there are no goalkeepers in chess or that a violin does not work very well as a hammer. Far more importantly, however, one should ask also: what is the evidence on the basis of which the claim that the 'procedure often falters' is made? What is the benchmark, in other words, against which the judgment call that the potential of successful resolution has been 'restrained' by the excessive flexibility of the Committee mechanism is made? The more closely one looks at it, the less convincing the argument seems to become - and not simply because such evidence, even if it were provided, would be very difficult to assess since it would be at best of anecdotal character. The real question is: what probative value would we have to assign to all those cases where no such evidence has been detected? Can the absence of a certain pattern of evidence - e.g. a bout of toothache suffered when eating apples or an international dispute escalating when dealt with through a flexible committee procedure itself be treated an evidence of something else - viz., that eating apples does not cause toothache and the use of flexible committee procedures does not escalate international disputes? The analytical dilemma this points to will be familiar to the students of public international law: it was exactly this conundrum that formed the central point of contention in the famous exchange between Thomas Franck and Louis Henkin in the early 1970s about the alleged effectiveness of A rticle 2(4) of the United Nations Charter. ${ }^{30}$ Should A rticle 2(4) be considered dead letter because in the years since its adoption so many states have gone to war so often $?^{31}$ Or should it rather be considered a perfectly successful legal regime because so many other states that could have gone to war during the same period did not and of those that did most have limited the scale of their military operations? ${ }^{32}$ Deterrence, like deliberate omission, is notoriously difficult to measure and to prove. Both interpretations seem, in

\footnotetext{
${ }^{29} \mathrm{lbid}$.

${ }^{30}$ See Thomas Franck, Who Killed Article 2(4)? Or Changing Norms Governing the U se of Force by States, 64 A IL 809 (1970); Louis Henkin, The Reports of the D eath of Article 2(4) Are G reatly Exaggerated, 65 AJ IL 544 (1971).

${ }^{31}$ Franck, supra n.30, 810-1: 'In the twenty-five years since the San Francisco Conference, there have been some one hundred separate outbreaks of hostility between states. The fact that on only one of these occasions has the United Nations been able to mount a collective enforcement action - and that more by a fluke than by dint of organizational responsiveness - indicates why, for security, nations have increasingly fallen back on their own resources and on military and regional alliances. [T] he failure of UN enforcement machinery has not been occasional but endemic, and so, concomitantly, has the resort to "self-defense". [S]ince there is usually no way for the international system to establish conclusively which state is the aggressor and which the aggrieved, wars continue to occur, as they have since time immemorial, between parties both of which are using force allegedly in "self-defense".'

32 Henkin, supra n.30, 544: The purpose of Article 2(4) was to establish a norm of national behavior and to help deter violation of it. Despite common misimpressions, A rticle 2(4) has indeed been a norm of behavior and has deterred violations. In inter-state as in individual penology, deterrence often cannot be measured or even proved, but students of politics agree that traditional war between nations has become less frequent and less likely. The sense that war is not done has taken hold, and nations more readily find that their interests do not in fact require the use of force at all. Expectations of international violence no longer underlie every political calculation of every nation, and war plans lie buried in national files. Even where force is used, the fact that it is unlawful cannot be left out of account and limits the scope, the weapons, the duration, the purposes for which force is used. Of the "some one hundred separate outbreaks of hostilities" to which Dr. Franck refers, less than fingersfull became "war" or successful conquest, and hundreds of other instances of conflict of interest and tensions have not produced even an international shot: cold war has remained cold, threats to the peace have remained threats, issues have remained only issues.' See also ibid., 547: '[T] he temptation to military intervention in internal affairs is largely the affliction of the few big Powers and even for them military intervention to promote or maintain internal wars is not al ways and everywhere possible.'
} 
principle, valid; that is, there is really no way of knowing which is the 'better' one. Choosing either over the other can hardly be justified in objective terms and is, thus, liable to give rise to charges of ideological bias.

The second standard solution involves the deployment of the WTO dispute settlement system (DSS). The background cultural reflex here is essentially that of a common lawyer crossing over into technocratic governance: the best way to resolve any given set of social problems is to leave everything to the wisdom of the case-law process. Eschew top-down legislative scenarios the same way a free marketeer would eschew economic planning, trust the decentralised logic of individual complaints to throw up all the relevant issues, look to the collective genius of the judicial profession to separate the gold from the dross, assemble the individual nuggets as they come - and then maybe, some years down the line, see if they could not perhaps be arranged together and fused into some kind of codifying document or a restatement.

For all its intuitive familiarity to the international legal mind, in the current ITL environment this approach appears to be the least popular. The conventional wisdom seems to be that at least in the case of NTBS the weaknesses of the WTO DSS consistently outweigh its strengths. Of course, the argument states, it is most definitely true that most policy solutions worked out in the context of a judicial process will usually have a far more rigorously constructed reasoning basis than those which have been developed in the context of diplomatic negotiations. And, of course, it is also true that such solutions will frequently further benefit from the higher transparency and predictability of the judicial process. However, the inductivist philosophy at the heart of the leave-it-to-the-courts approach unavoidably makes it a very slow-moving process, especially when it comes to major policy issues - it may take well upwards of a decade before enough starting material is accumulated for any kind of restatement to become possible - and time in the present context is absolutely of the essence:

Exporters facing NTBs need real time solutions. A solution that comes 2 years after the identification of the problem does very little to assist exporters in clearing their goods at the port of entry and only adds to costs and leads to a loss of market opportunity. The lengthy dispute settlement mechanism can ... create considerable instability especially for a new enterprise in the exporting country. ${ }^{33}$

What is more, even at the micro-level the judicial process can hardly be said to work well. It is a well-known fact, that the use of the WTO DSS is a very resource-intensive undertaking, both in terms of the amount of time it takes before an average dispute reaches resolution and in terms of the sheer scale of financial and legal-labour resources that the involved parties would have to expend to get there. No less importantly, continues the argument, routing the dispute resolution process through a litigative channel by definition will typically encourage the participating players to assume a fundamentally adversarial attitude vis-à-vis one another, which, of course, is not at all conducive to the achievement of swift pragmatic resolutions and, indeed, under some circumstances can lead to an even greater resource wastage pattern (digging of the heels scenario). ${ }^{34}$

\footnotetext{
${ }^{33}$ See 'Resolution of NTBs through a Facilitative M echanism', supra n.13, $\S 5$.

${ }^{34}$ See Fraser, supra n.4, 1041.
} 
Note the hidden pop psychology turn (another classical trait of ideological discourses): the claim about the counterproductive effects of the litigative experience, though it is couched in decidedly empirical terms, is backed up neither by any quotable empirical evidence nor by data derived from any kind of practical trials or experiments. The idea is simply parachuted into the argument in the form of a bold deductive assertion, having been borrowed, one suspects, from an apparently similar context in which the matter at hand was the study of the psychological impact of litigative experiences on human individuals and business enterprises - if it holds true for those kinds of litigants, why should it not also hold true for states? - the promiscuity of unreflective domestic analogism at its best. ${ }^{35}$

Note also the lack of any recognition when it comes to providing account of any potential cultural differences between the different categories of WTO members: going by this theory, the litigative experience appears to have the exact same effects on German trade officials as it would on their Chinese or Q atari counterparts.

The secret of the ideological discourse is that it al ways seems to work unless one knows what to look for to see if it doesn't. If one does not know what is missing from its construction the empirical evidence, the justification for the domestic analogy, the recognition of cultural differences - the anti-DSS argument offered by the HM discourse reads actually quite elegantly:

\begin{abstract}
While it should be recognized that the WTO's [DSS] is a distinct improvement over the erstwhile GATT procedures due to its predictability and enforceability, as well as being one of the most efficient mechanisms available under international legal regimes, the [DSS], which works on the principles of an adversarial process, is expensive, and the time of up to 2 years taken for an enforceable decision, often frustrates the exporter's need for a timely solution. ${ }^{36}$
\end{abstract}

So far, so good, except: is it not true that a significant part of the DSS procedure does not, in fact, rely on any kind of adversarial dynamics? Neither the initial consultations stage, nor the 'good offices, conciliation and mediation' stage - nothing, in fact, that is covered by A rticles 4 and 5 of the WTO Dispute Settlement Understanding - is premised on any form of litigative confrontationism. W hat should one make of that fact?

The answer might have been far from obvious under some other circumstances, but not so in the world of pop psychology. The thing is, explain the authors of the 2009 briefing note, al though the consultations procedure may not look the same as a normal litigative procedure in reality it actually is that: 'the formal step of submitting a request for consultations' al ready 'frame[s] the discussion in a legal and adversarial direction'. ${ }^{37}$ The damaging effect, in other words, is produced already at the moment the earliest stage of the DSS process is initiated; there is no need to wait until the panel is established or the A ppellate Body is engaged.

Note again the lack of any quotable empirical evidence and the avoidance of the cultural variety question: once more it does not seem to matter which member states may be involved

\footnotetext{
${ }^{35}$ For an overview of the bleak history of unscrupulous use of domestic analogism in international law, see ANTHONY CARTY, THE DECAY OF INTERNATIONAL LAW? A REAPPRAISAL OF THE LIMITS OF LEgaL IMAGINATION IN INTERNATIONAL A fFaIRS (1986). See, in particular, ibid., 67-80 and 87-92. See also for related comment A kbar Rasulov, 'Theorizing Treaties: The Consequences of the Contractual A nalogy', in CHRISTIAN TAMSET AL. (EDS.), RESEARCH HANDBOOK ON THE LAW OF TREATIES 74 (2014).

${ }^{36}$ See 'Resolution of NTBs through a Facilitative M echanism', supra n.13, para. 4.

37 See 'A nswers by co-sponsors', supra n.23, para II.2.
} 
in the consultations procedure, the phenomenological effects in question - the arousal of an adversarial sensibility - will always be the same.

Note also the latent circularity at the heart of the proposed explanation: what the 2009 sponsors are essentially saying is that the act of starting a process that the involved parties perceive as a litigative process triggers in their minds an experience of this process as a litigative process. But of course: the act of starting something that I know is a form of dancing is going to lead me - because I al ready know that I am dancing - to realise that I am dancing.

Note, finally, the curious attempt to equate in the latter part of the formulation 'legal' with 'adversarial'. A stickler for detail might note that while the latter concept usually describes a certain way of arranging the mechanics of judicial procedure, the former tends to cover a much broader field of phenomena, but this would be precisely to miss the whole point of what seems to be the implied argument: the damaging effects that were mentioned earlier are really a product not of the DSS itself but of the idea of law. It is not so much, in other words, the immediate organisation of the DSS procedure that is supposed to cause the member states to develop a deep-seated predilection for belligerence and an uncontrollable urge to dig their heels in. It is the introduction of the concept of law into their heads and the notion that their dispute should be resolved according to their legal rights.

Thus put, the animating argument behind this part of the HM discourse may seem truly absurd, but, of course, that is precisely what (almost) all ideologies have in common: a certain fondness for fundamental absurdity and deep-seated theoretical bankruptcy. The only thing that separates the more successful ideologies from the less successful ones in this context is how effectively this combination of absurdity and theoretical bankruptcy has been covered up by the use of clever discursive devices.

The third archetypal scenario recognised in the eyes of the contemporary ITL doctrine is the harmonization of the corresponding member states' internal regulatory regimes. A $n$ ounce of prophylactic is worth a gallon of medicine. The WTO Committees and the DSS may help resolve individual NTB disputes after they break out, but '[t]he harmonization of the $M$ embers' [domestic regulatory regimes] has the effect of limiting and preventing disputes on specific NTB measures' before they even become possible. ${ }^{38}$

How does this process work? The argument, in a nutshell, seems to go more or less as follows: every NTB dispute is ultimately a symptom of an underlying discrepancy in the respective regulatory regimes. The more similar the regulatory regimes adopted by the different member states are, the less likely their application in practice is going to produce a disproportionate effect on cross-border trade, the less likely, accordingly, their execution is going to raise a protectionist NTB. If the ultimate aim of the ITL enterprise is to reduce and eliminate the harmful effects of NTBs on international trade, the most effective strategy the ITL enterprise can adopt in the long run, it follows, must be the promotion of an everdeepening process of regulatory harmonization.

${ }^{38}$ Fraser, supra n.4, 1036. 
Note the implied assumption behind this argument: what gives NTBs their trade-destructive power, on this vision, comes down essentially to a loose combination of informational asymmetries and a collective action problem, both of which are species of what in modern economics is loosely described by the broad label transaction costs. The informational asymmetries hypothesis proceeds from the fairly commonsensical observation that it would be considerably more difficult for Ruritanian toy manufacturers to find out about A rcadian toy safety standards and certification procedures than it would be for the Arcadian toy manufacturers. The collective action hypothesis, in turn, revolves around the idea that even though it may be ultimately in the interests of the Ruritanian toy industry as a whole to institute a regime of information gathering and dissemination about the A rcadian toy safety standards and to establish on its basis some kind of pre-certification procedure modelled on the applicable Arcadian regulations which could be used by the Ruritanian exporters whenever they need it, only very few Ruritanian toy manufacturers will find it both feasible and economically sensible to invest in either of these undertakings; the rest will either take a leap of faith and try to export their products to the A rcadian market without the assurance of having gone through such a procedure or will avoid exporting into that market altogether. Either scenario, obviously, is going to result in sub-optimal trade patterns. Hence the need for a global-level public institution-style solution, such as, for instance, the establishment of a comprehensive notification mechanism under the respective WTO Committees, or the promotion of an equally comprehensive programme of transnational harmonization of standards.

Why is it important to take notice of this imaginational pattern beyond the fact that it confirms the presence of a strongly ideologised climate within the ITL discursive space? The answer, in a sense, is as old as the critical tradition itself: to a man with a hammer every problem that does not look like a nail is fated to remain either incomprehensible or invisible.

If the general theory against the background of which the contemporary NTB debate unfolds is premised on the notion that to solve the problem of the NTBs one must only manage the question of transaction costs, then a large part of what might be called openly strategic and heavily politicised behaviour will simply not register within that debate's horizon of internal visibility or will be received into it in a fundamentally misrecognised form. Indeed, the only variety of open politicisation scenario which the currently dominant theory of trade policy decision-making appears to be able to recognise is the classical capture-by-special-interests scenario. And the first thing, of course, that needs to be noted about this kind of scenario is that it is essentially premised on two assumptions: (i) that national governments typically have no capacity and no real inclination to determine the course of their political action in the global trade policy-setting arena independently of the respective domestic interests under whose pressure they act; and (ii) that the single dominant rationality at the heart of all global trade policy processes is the rationality of managerialism and economic calculation - as opposed to, say, OPEC-style or Russian-style geopolitical games as seen, for example, in the 1970s oil crisis or in the recent cases of Moldovan and Georgian wine embargoes. A theoretical apparatus that is grounded in such a remarkably impoverished model of political behaviour (and social life more broadly) and so fundamentally predisposed towards ignoring the role of non-economic factors and considerations in the development of global trade policy can, of course, still equip its users to form relatively well-informed judgements about the operative logic of the international trade regime - but only up to a certain point. Beyond that it is bound inevitably to turn into a fundamental epistemological obstacle and thus become a source of serious practical impediment and danger both to these users themselves and to those wider publics whose lives may be affected by their choices and decisions. 
A somewhat different way to make the same point would be to say that the exact same imaginational pattern that can be seen in the present context can also be detected on a slightly larger scale in the case of the so-called Liberal Theory of International Relations - as expounded by the likes of Anne-M arie Slaughter and Andrew Moravcsik ${ }^{39}$ - and Harold Koh's transnational legal process school. ${ }^{40}$ Everything that has been said about the miscellaneous dark sides, blind spots, and pop-science dilettantism tendencies of these schools, ${ }^{41}$ it follows, can be extended logically to this aspect of the NTB debate as well - and, by extension, to the corresponding region of the contemporary ITL consciousness too, out of which the HM initiative has arisen and by the internal contradictions of which its discourse is structured and over-determined.

\section{The Proceduralist Turn and Its Discontents}

What is the importance of all these observations? One way of answering this would be to say that what the discussion above shows is essentially that the emergence of the $\mathrm{HM}$ enterprise in modern ITL is an event that cannot really be understood on its own terms. It is, in other words, something other than what it makes itself out to be. The argument made on behalf of the new HM procedure by its sponsors seems fundamentally unconvincing if it is taken at its face value - both as a policy proposal and as a hypothesis about NTB disputes and, quite possibly, the ITL IDS logic more generally. What the new mechanism is supposed to contribute to the WTO IDS system is, in fact, neither so novel nor so radically different as its sponsor seek to present it: the WTO procedural framework al ready has all of those elements which the HM initiative aims to introduce within it; what is more, it is neither so inefficient nor so disorganised as it commonly tends to be portrayed.

If it cannot be understood on its own terms, how ever, the question then arises: how should it be understood? How should we read the appearance - the coming-into-existence - of the HM policy exercise? M y sense, dictated no doubt as much by my scholarly habits as by anything else, is that the most convincing answer to this would be that we should read this kind of 'events' symptomatically, that is to say, as reflections, traces, and expressions of some broader underlying process - and not necessarily one of a ruptural nature. What could this process be in the present case? The answer, I think, has to be sought for the most part outside the immediate horizon of the present-day ITL enterprise.

If we look closely at the operative dynamics animating the $\mathrm{HM}$ discourse, its basic self-image essentially seems to be that of a fundamentally technocratic enterprise pre-occupied with the question of process-building. The main debate at its heart is presented as an entirely apolitical

\footnotetext{
${ }^{39}$ See, e.g., A ndrew M oravcsik, Taking Preferences Seriously: A Liberal Theory of International Politics, 51 Int. Org. 513 (1997); A NNE-M ARIE SLAUghter, A NEW W ORLD ORDER (2004).

${ }^{40}$ See, e.g., Harold Hongju K oh, Bringing International Law Home, 35 H ous. L. Rev. 623 (1998).

${ }^{41} \mathrm{~A}$ good place to start reconstructing such a critique would be CHANTAL M OUFFE, THE DEM OCRATIC PARADOX (2000). For a slightly different starting point, see M ark K elman, M isunderstanding Social Life: A Critique of the Core Premises of "Law and Economics", 33 J. Leg. Educ. 274 (1983). Otherwise, see K oskenniemi, supra n. 2 (on the new managerial ethos in international studies). See also David K ennedy, The Disciplines of International Law and Policy, 12 Lei. J. Int'I L. 9 (1999) and David Kennedy, The Politics of the Invisible College: International Governance and the Politics of Expertise, 2001 EHRLR 463 (2001) (on the politics of not-seeingpolitics and dark sides more generally).
} 
debate about process and procedure. All the various issues, dilemmas, and aporias which it throws up are similarly formulated as entirely apolitical issues, dilemmas, and aporias of process and procedure. Even the ultimate foundational challenge towards which everything is orientated is consistently articulated in the fundamentally apolitical form of: 'W hat is the best way to organise the processes and procedures of ITL IDS?' The whole enterprise of the HM initiative, it seems, is, in effect, constructed as just another phase in the grand technocratic exercise dedicated to the improvement and optimisation of the ITL process.

A nd yet all these presentations, formulations, and articulations, it seems to me, are ultimately just that: interpretative spin, flimsy appearances, carefully constructed façades - nothing more. The reality behind them is entirely different, a lot more complex, and a lot more ambivalent too. To see what that reality is, one needs first to take the proverbial few steps back and try to insert the HM discourse into the framework of a somewhat broader discursive formation than the one in whose context it has heretofore been considered: that of the contemporary Public International Law (PIL) system as a whole, rather than just the presentday ITL enterprise - for it is, indeed, that formation whose operative conditions actually determine the productive logic of the ITL IDS debate and define the general thrust behind the $\mathrm{HM}$ enterprise. Such is the task and there exists probably no better platform from which to begin addressing it than David K ennedy's International Legal Structures. ${ }^{42}$

$* * * *$

Kennedy's starting thesis is very simple: proceeding on the assumption that the contemporary PIL discourse does, in fact, constitute - as most of its participants appear to believe - an internally coherent system, it seems it would be useful to try to comprehend the achievement of this coherence as a function of its underlying structure. The most intuitively obvious way to determine the essential contours of this structure would be to trace the various internal divisions of PIL's doctrinal field as reflected in the second-order discourse produced by PIL commentators.

Having set out with this general aim, Kennedy's next step was to identify which of these internally recognisable divisions could shed the most light on the productive logic of the PIL discourse. A fter entertaining several different possibilities, ${ }^{43}$ he eventually decided to focus on the tri-partite split between 'three broad categories which I termed sources, process and substance'. ${ }^{44}$ The logic of giving them these names did not, of course, come from a simple division of functions between the three doctrinal blocks:

I did not decide to work with these categories because I thought they addressed different problems, or had developed in response to different historical or functional demands, or because they seemed to apply in different contexts. Indeed, commentators seem[] to treat them as the product of similar forces, and doctrines from each category often seem[] equally applicable to a wide range of factual situations. It was precisely this generalizability which suggested that they all formed part of the contemporary discourse of public international law. ${ }^{45}$

\footnotetext{
42 See David Kennedy, International Legal Structures (1987).

${ }^{43}$ See, e.g., David K ennedy, Theses about International Law Discourse, 23 G.Y .I.L. 353 (1980).

${ }^{44}$ See KENNEDY, supra n.42, 289.

${ }^{45} \mathrm{lbid}$.
} 
What makes the three blocks into a single whole, in other words, is not so much the fact that there exists, at some abstract level, a formal division of labour between the respective doctrinal sub-systems. Quite on the contrary: at any given point any given factual issue that is submitted to a PIL analysis can lend itself to being treated through the prism of any one of these sub-systems simultaneously. What to one PIL practitioner, thus, may look like a question of substance, to another may well seem a question of process or a question of sources. The interchangeability of the framing perspectives in this sense constitutes a key defining characteristic of the PIL system for K ennedy.

Each of these doctrinal groups, however, seemed to be characterised by a distinctive rhetorical style and self-image. Each seemed eager to differentiate itself from the others. U sually commentators and treatise writers complied by treating them distinctly in the order in which I consider[] them here. I decided to do likewise, partly because I was interested in examining just such rhetorical self-images or purports. After looking at these materials in this way, it has become possible to think about the overall coherence of public international law as a set of relationships among these discursive fields. Indeed, it is striking how effectively these distinctive fields, each with its own characteristic doctrinal structure and argumentative style, work with and against one another to generate and sustain an international legal system. ${ }^{46}$

To understand how this regime of 'working with and against one another' is actually organised in practice, it is essential to take account of another very important feature of the PIL discursive tradition: the objective organisation of the PIL discursive structure does not for the most part match the projected imagery of that structure which animates its practical deployment. That is to say, while in the former context all three sub-systems operate as 'equal partners', in the latter context the relationship between them is governed by a certain sense of hierarchy. Process and sources

present themselves as servants of a substantive order which will be achieved and protected [with their help]. We expect little of process - and even less of sources - because we expect so much of substance. In substantive legal doctrine we hope to find a social fabric of resolution and peace - the wise constraints which keep us free. Substance should reflect and create a social order which can be elaborated by sources and served through process. In this sense, the discourses of process and sources call for and project a substantive normative order. ${ }^{47}$

The discourse of process, in particular, seems to be dominated by this spirit of instrumentalism and subservience to substance. Its basic organisation, remarks K ennedy, is fundamentally defined by its implicit aspiration 'to be both outcome determinative ... and to remain open and responsive to those who participate in it - to remain neutral with respect to substantive outcomes', to refrain from prejudging substance's w ork. ${ }^{48}$ Drawing its legitimacy from the idea that it strives to create a system that is simultaneously open and closed, ${ }^{49}$ the process discourse thus finds itself constantly attracted towards the ethos and the aesthetics of

\footnotetext{
${ }^{46} \mathrm{Ibid}$.

47 Ibid., 195.

${ }^{48}$ Ibid., 188.

${ }^{49}$ Ibid., 290.
} 
technocracy. It buttresses itself by regularly referencing, on the one hand, the incontrovertible authority of state consent from which it arises and which it seeks to harness and channel into a practical institutional reality, and by constantly invoking, on the other hand, the breathtaking promises of the substantive regime to-come - a system of clear definite answers to every substantive question about the international legal right(s) and wrong(s) - the crystallisation of which it is meant to facilitate. The reality that is concealed by these twin manoeuvres, argues Kennedy, however, is that all this, in a sense, is a con job: the ideology of process is a regime of false consciousness, distortion, and manipulation.

The discourse of substance never delivers on its grand promise. At any given point in time it offers to its participants the possibility of supporting several equally valid answers to any given question without indicating which of them should be privileged over the others. Is Mexico's low minimum wage scheme an unfair 'subsidy' and part of a strategy that enables 'dumping' on the part of the Mexican manufacturers when the export to US markets? Or is it rather the case that the US insistence on the observance of higher labour standards is a form of NTB? B oth interpretations are possible; how one goes about adjudicating between them depends in large measure on one's ideological preferences and unstated background assumptions about what is 'good' and 'normal'. 50

The only way in which the PIL tradition knows how to escape this kind of antinomian vortex without stepping 'outside law' is by reframing the respective questions of substance as questions of process and sources. The implicit assumption there seems to be that whenever one runs into a logically irresolvable indeterminacy one should opt for that solution which either (a) is supported by a better/longer/more 'hard-legal'/more fundamental-principlesreinforcing/more authoritatively verifiable sources pedigree; and/or (b) originates in a better/more inclusive/more transparent/more rigidly structured/more flexible process. What rules of international law are part of jus cogens? Whatever the international community of states as a whole decides to accept and recognise as such. What does the concept of a threat to international peace and security mean in practice? Whatever the UN Security Council, while acting according to the procedure determined by Chapters V, VI, and VII of the Charter, decides it means. How should one understand the non-attribution requirement in the WTO law of safeguards? The official definition - that the alleged 'serious injury' in question should be attributable directly to the alleged 'increase in imports' and not some other factor is so abstract and impractical - try applying this test literally amidst an ongoing economic crisis - it seems virtually useless. How can this problem be resolved? A gain, the solution proposed by the ITL practice could not be clearer: the principle of non-attribution in the law of safeguards has effectively been converted into a series of procedural requirements (rituals of process) that have to be complied with by the respective investigating authority before it can safely apply the desired measures.

The problem with such an escape strategy, points out Kennedy, however, is that, firstly, it threatens to bring about the disappearance of substance: '[0]nce substantive issues are presented in this way, substance discourse loses its [distinctive identity]. A ny such resolution projects the conflict into sources or process by harnessing the substantive doctrinal scheme of categories to modes of authority. ${ }^{51}$ In the second place, and far more importantly, to the extent to which this strategy can work at all, it can only work temporarily, i.e. until the point

\footnotetext{
${ }^{50}$ See David K ennedy, 'The "Rule of Law", Political Choices, and Development Common Sense,' in DAVID M . Trubek and Alvaro Santos (eds.), The New Law and Economic Development 95, 140 (2006).

${ }^{51}$ See K ENNEDY, supra n.42, 198.
} 
when someone starts to recognise - as M artti Koskenniemi explains, they inevitably will ${ }^{52}$ that the indeterminacy challenge is no less pressing on the other side of the fence. The only thing that changes when the relegated question of substance arrives in the domains of process and sources is the list of immediate options in terms of which the 'new' indeterminacy challenge is going to be structured. The antinomian pressure underpinning it remains exactly the same. D epending on the quality of the legal talent involved and the reactionary pressures exerted by the vested interests, the coming-to-consciousness of this process may take some time. Sooner or later, however, the real isation inevitably surfaces that, just like the discourse of substance, so too the discourses of process and sources enable their practitioners at any given point in time to produce several mutually contradictory and - from the strictly legal point of view - equally valid solutions to any given question posed before them. The only meaningful way the PIL tradition enables them to escape such aporias is by relegating the respective controversies into the neighbouring domain.

And thus, explains Kennedy, the vicious circle at the root of the PIL discursive system gradually becomes revealed: ' we find ourselves continually referred back [from substance] to process and sources while they refer us forward to substance'. ${ }^{53}$ The politics this creates has a highly distinct ideological signature: so long as the awareness of the vicious circle remains limited to a relatively narrow community of the disciplinary insiders,

the rhetorical system as a whole is able to assert itself quite firmly ... while sustaining a very humble and deferential tone. [It creates the impression of] a quite well articulate and complete legal order even though it is difficult to locate the authoritative origin or substantive voice of the system in any particular area. ... Sources refers us to the states constituted by process and grounded in the violence defined and limited by substance. Process refers us to its origin in sources and its determination in substance. Substance refers us to the boundaries of process, its origins in sources and its resolution in an institutional system of application and interpretation. Thus, the variety of references among these discursive areas always shrewdly located the moment of authority and the application in practice elsewhere. ${ }^{54}$

What is more, even though at the most abstract level the basic distinction between the three sub-systems may often be experienced by the respective discursive agents as something quite tangible and definite, the actual sets of rhetorical strategies that are encountered in each case seem to be exactly the same. ${ }^{55}$ There is, in short, not much that really separates the rhetoric of process from the rhetoric of substance and the rhetoric of sources. ${ }^{56}$

For K ennedy, the main lesson that could eventually be extracted from this discovery was the promise of a new disciplinary imaginary: 'If, as it seems, a rather small set of argumentative maneuvers and doctrinal distinctions repeat themselves in a wide variety of different contexts throughout public international law, it might be possible to unite the field around these

\footnotetext{
52 See Martti Koskenniemi, From Apology to Utopia: The Structure of International Legal ARGUMENT (rev. edn.; 2006).

53 KENNEDY, supra n.42, 196.

54 lbid., 293.

${ }^{5}$ Ibid., 291: '[T] 0 a surprising extent, the rhetorical patterns characteristic of each discourse - indeed, which seem[] to characterize that discourse - seem[] to repeat themes and references familiar from other areas. This [is] most apparent in the return of the law of force to doctrines about sources. Although these two fields seem[] very distinct - sources a very doctrinal, logical field, the law of force a very substantively engaged field - both seem[] to be concerned with invoking and the muffling the sovereign authority behind its most basic principles.' ${ }^{56}$ For the same argument, see al so generally K OSKENNIEM I, supra n.52.
} 
patterns rather than to be forced to think of them each time anew in response to different situations or in different doctrinal areas. ${ }^{57}$ For us, in our present context, however, it seems to be something else.

\section{Conclusion}

It should not be too difficult to guess where this argument goes next. The self-image projected by the HM discourse is grounded in a very important but entirely unacknowledged assumption that has come to take root in recent years across the whole field of the contemporary ITL enterprise. The triggering event that led to this development was the longterm failure of, to use Kennedy's vocabulary, the 'substance discourse' project in modern $I T L$. In a recent book Andrew Lang masterfully documents the various instances of this failure and how it has come to be realised by the actors concerned across the different areas of the GATT/WTO regime, from the TBT agreement to the A rticle XX jurisprudence. ${ }^{58}$ The combined effect of these developments, argues $L$ ang, has been the emergence of what he describes as the 'proceduralist turn' in modern ITL: ${ }^{59}$ the half-unconscious decision by the ITL community to deploy the discourse of process as a functional replacement for the discourse of substance, to try to tackle, in other words, the apparently unsolvable questions of substance, such as what types of non-tariff measures should be allowed and encouraged and under what circumstances, by reformulating them as questions of process.

Looking from this angle, the underlying sensibility by which the proceduralist turn has been inspired appears to be grounded in a deep practical contradiction. On the one hand, it seems extremely naïve in its theoretical self-image: the latent message against the background of which it unfolds seems to be that we are only having this conversation about the NTB IDS process because we have not (as yet) been able to work out the correct substantive answer to the question of what kind of domestic regulations are legitimate and what kind are not. On the other hand, it also seems to be deeply strategic, not to say cynical, in its broader political gamble: so long as the ITL community continues to act as though a legal answer to the question of NTBs can be worked out, the political challenges raised for the ITL enterprise by everything from its determining that this might be a 'question' at all to endorsing the use of such a suspiciously elastic category as 'NTBs' as a legal standard can be deferred virtually indefinitely. What happens in the meantime under the cover of this endless deferral - what sort of distributive outcomes become possible, entrenched, and gradually normalised and who gets to benefit from that - is, of course, an entirely separate matter.

The current debate about the HM initiative presents itself - and is most probably completely sincerely experienced by its participants - as an essentially technocratic debate about process and procedure. In reality, as Kennedy's analysis of the PIL discursive system suggests, it functions as a discursive prism which refracts a regime of policy contestation far more extensive in its scope and far more complex in its real-world effects.

On its surface, it presents itself as a debate which operates on the explicit premise that the challenges placed at its heart can be eventually resolved and thus the debate itself be brought to an end. The reality, however, seems to be that this is not at all the case: and not just

\footnotetext{
${ }^{57}$ KENNEDY, supra $n .42,291$.

${ }^{58}$ See AndReW LANG, W ORLd Trade LaW After Neoliberalism (2011).

${ }^{59}$ See in particular the discussion in ibid., 313-53.
} 
because that regime of policy contestation for which it acts as the refracting discursive prism is far too complex and multi-layered, but because neither the challenges themselves nor the debate which has developed around them are actually capable of reaching any logical, objective, and impartial resolution. A ny termination that can be brought to them, thus, is liable to remain effective only so long as the underlying convergence of political interests is stable and functional. In the present day and age, the possibility of such a convergence achieving any degree of longevity, while at the same time retaining its practical functionality at a sufficiently high level to enable to freezing of such kind of policy contestational environments, seems fundamentally unlikely. The good news is that this means the services of ITL professionals are certain to remain in high demand. What happens under the cover of this good news, though, is again an entirely separate matter. 